\title{
Healing and prevention of relapse of reflux oesophagitis by cisapride
}

\author{
J Toussaint, A Gossuin, M Deruyttere, F Hublé, G Devis
}

\begin{abstract}
Altogether, 138 patients were included in a study aimed at evaluating the effect of cisapride on healing and relapse of oesophagitis shown endoscopically. In the first phase of the study cisapride was given in an open fashion at $\mathbf{1 0} \mathrm{mg}$ four times a day for $\mathbf{8}$ to $\mathbf{1 6}$ weeks, and healing was obtained in $69 \%$ of patients. Healing occurred later in patients with grades II to IV oesophagitis. The total score for reflux symptoms decreased by $67 \%$. Eighty of the healed patients were included in the second phase. They were randomly assigned to double blind treatment with either cisapride $10 \mathrm{mg}(\mathrm{n}=37)$ or placebo $(n=43)$ twice a day. Control endoscopy was performed when symptoms recurred or at the end of the six month trial. The cumulative percentage of patients in remission was higher $(p=0.06$, survival analysis) in the cisapride group than in the placebo group, the relapse rates being $20 \%$ and $39 \%$. The duration of remission tended to be longer in patients with a lower initial degree of oesophagitis. Adverse effects were no more frequent with cisapride than with placebo. In conclusion, cisapride is efficacious in healing oesophagitis, and, unlike other gastrointestinal prokinetic drugs or low dose cimetidine (400-800 $\mathrm{mg}$ daily) or ranitidine (150 mg daily), it may prevent relapse of oesophagitis.
\end{abstract}

Reflux oesophagitis usually runs a chronic or recurrent course. In terms of patient management this implies that both curative and prophylactic treatment may be necessary. Several approaches have produced favourable results in the short term medical treatment of oesophagitis. ${ }^{1-3}$ Acid suppressing drugs acting through $\mathrm{H}_{2}$ receptor blockade and to an even greater extent $\mathrm{H}^{+} / \mathrm{K}^{+}$adenosine triphosphatase inhibitors have proved efficacious in healing oesophagitis. The problem of pathogenetic factors of reflux disease other than acid - that is, deficient barrier function of the lower oesophageal sphincter, decreased oesophageal clearance, or delayed gastric emptying - has been successfully addressed with gastrointestinal prokinetic agents. In this respect the effects of cisapride have been well documented..$^{45}$ Cisapride $10 \mathrm{mg}$ four times a day for 6 to 16 weeks produced endoscopic cure rates of $56 \%$ to $89 \%$, being significantly superior to placebo ${ }^{67}$ and at least comparable to cimetidine and ranitidine.$^{89}$

Whereas healing can be achieved in most patients, few remain in remission after treatment is discontinued. Endoscopic relapse rates between approximately $40 \%$ and $80 \%$ have been observed six months after healing with $\mathrm{H}_{2}$ blockers or omeprazole. ${ }^{10-12}$ Acid suppressing drugs, given at maintenance doses - that is, usually half the healing dose - have not been shown to be efficacious in preventing relapse of oesophagitis, ${ }^{12-23}$ and no studies are available to document the longterm efficacy of prokinetic drugs. Therefore, a prospective study was performed in which (i) healing of oesophagitis and possible influencing factors were established during open cisapride treatment and (ii) relapse rates during treatment with either cisapride or placebo were determined in healed patients.

\section{Methods}

\section{PATIENTS}

The trial was conducted in accordance with the Declarations of Helsinki and Tokyo and was approved by the local ethics committees. All patients gave their consent to participate. Outpatients, aged between 16 and 75 years, with endoscopically diagnosed oesophagitis were recruited. Oesophagitis was defined as oesophageal inflammation characterised by macroscopical mucosal defects - that is, erosions (lesions covered with fibrin) or ulcers, or both and was scored as grade I (isolated erosions), II (longitudinal erosions), III (circumferential erosions), or IV (ulcer at Z-line, with or without erosions), in the presence of squamous epithelium or columnar epithelium (Barrett's dysplasia) in the distal oesophagus. Patients with grade 0 (normal oesophagus or presence of red spots or streaks) and patients with a suspended ulcer or with Barrett's ulcer were excluded. Patients were not included in the study if they had pancreatic, severe hepatic, pulmonary, or cardiac disease, or a malignancy that might interfere with the study, previous abdominal surgery except for abdominal wall hernia repair and appendicectomy, or if they had used $\mathrm{H}_{2}$ blockers, antacids, gastrokinetics, or anticholinergics regularly in the four weeks preceding the trial. Heavy smoking ( $\geq 40$ cigarettes per day) and heavy drinking ( $\geq 80 \mathrm{ml}$ alcohol per day) were also reasons for exclusion.

A total of 163 patients were entered into the first phase of the trial; 25 patients were lost to follow up and excluded from the efficacy analysis. In one of them treatment was discontinued because of adverse effects (mild nausea and dizziness for two days). Table I gives the main characteristics of the 138 patients included in the trial. Nearly two thirds had previously experienced an episode of oesophagitis. The curative treatment in this episode had consisted of $\mathrm{H}_{2}$ blockers in about two thirds of the patients, antacids in $21 \%$, and gastrokinetics in $11 \% . \mathrm{H}_{2}$ blockers and gastrokinetics had been given for a 
TABLE I Characteristics of patients included in the efficacy analysis

\begin{tabular}{|c|c|c|c|}
\hline & \multirow{2}{*}{$\begin{array}{l}\text { Healing } \\
\text { phase } \\
(n=138)\end{array}$} & \multicolumn{2}{|c|}{ Maintenance phase } \\
\hline & & $\begin{array}{l}\text { Cisapride } \\
(n=37)\end{array}$ & $\begin{array}{l}\text { Placebo } \\
(n=43)\end{array}$ \\
\hline $\operatorname{Sex}(M / F)$ & $82 / 56$ & $23 / 14$ & $20 / 23$ \\
\hline Age (years) (mean (SD)) & $52(14)$ & $52(14)$ & $51(13)$ \\
\hline Weight $(\mathrm{kg})($ mean $(\mathrm{SD}))$ & $73(12)$ & $74(10)$ & $71(12)$ \\
\hline Smoking (cigarettes/day): & 34 & 7 & \\
\hline$\leq 10$ & & 5 & \\
\hline $11-25$ & 15 & 2 & 7 \\
\hline$>25$ & 2 & $=$ & \\
\hline \multicolumn{4}{|l|}{ Regular alcohol consumption } \\
\hline$(\mathrm{m} \mathrm{l} / \mathrm{day}):$ & 35 & 8 & 13 \\
\hline$\leq 20$ & 25 & 4 & 11 \\
\hline $21-40$ & 6 & 4 & 1 \\
\hline \multirow{2}{*}{\multicolumn{4}{|c|}{ Previous episode of oesophagitis }} \\
\hline & & & \\
\hline (grade $\left.)^{\star}\right):$ & 97 & 29 & 31 \\
\hline & 12 & 5 & 2 \\
\hline II & 25 & 9 & 6 \\
\hline IIII or IV. & 5 & 2 & 1 \\
\hline & 55 & 13 & 22 \\
\hline \multicolumn{4}{|l|}{$\begin{array}{l}\text { Oesophagitis in present trial } \\
\text { (grade })^{2}\end{array}$} \\
\hline I & 53 & 17 & 13 \\
\hline & 72 & 16 & 25 \\
\hline III or IV & 13 & 4 & 5 \\
\hline
\end{tabular}

*I= isolated erosions; $\mathrm{II}=$ longitudinal erosions; $\mathrm{III}=$ circumferential erosions; IV=ulcer at $Z$-line.

median duration of three months, and antacids for six months. In half of the patients with a previous episode maintenance treatment had been started mainly with antacids (in $60 \%$ of this group) or $\mathrm{H}_{2}$ blockers (in $30 \%$ ), and in only a few patients with gastrokinetics.

\section{TREATMENT}

The patients entered into the trial were to be treated under open conditions with oral cisapride $10 \mathrm{mg}$ four times a day (before the three main meals and before bedtime) for at least eight weeks. Patients who still had grades I to IV at week 8 were continued on the drug. If healing (grade 0) had not been achieved by weeks 12 to 16 the trial was discontinued. Patients who were healed at weeks 8 to 16 were immediately put on the double blind maintenance phase. They were assigned in accordance with a computer randomisation list to treatment with either cisapride $10 \mathrm{mg}$ or matching placebo tablets twice a day (before lunch and before bedtime) for six months or until relapse of oesophagitis (to grade I or higher) was shown endoscopically, whichever occurred first.

The use of antacids was discouraged but tablets with an acid neutralising capacity of between 20 and $30 \mathrm{mEq} \mathrm{H}^{+}$per tablet - for example, magnesium hydroxide, aluminium hydroxide, $25 \mathrm{mEq} \mathrm{H} \mathrm{H}^{+}$- could be taken if pain was unbearable. The remaining tablets were counted at the end of the treatment period to check on compliance with the test medication regimen and the use of antacids was checked. The following drugs were not allowed during the study: cholinergics, anticholinergics, other gastrokinetics, major neuroleptics, antiemetics, $\mathrm{H}_{2}$ blockers, sucralfate, and alginates.

\section{ASSESSMENTS}

Endoscopy was performed at entry to the trial, at week 8 of the healing phase and at weeks 12 to 16 if no healing was obtained at week 8 , and at the end of the six month maintenance phase. If, however, moderate or severe symptoms recurred daily or if antacids needed to be used for more than three days in a row before the end of the six months patients were to report to the investigator and a control endoscopy was performed. If on that occasion oesophageal lesions were found, treatment was discontinued, the end point of the trial having been reached.

At each visit the frequency and severity of 12 symptoms were assessed: four symptoms of reflux (daytime and night-time heartburn and regurgitation) and eight symptoms of postprandial epigastric discomfort (postprandial fullness, epigastric distension, epigastric pain, eructation, early satiety, postprandial nausea, vomiting, and anorexia). Severity was rated 0 (symptom absent), 1 (mild: patient only aware of symptom on being prompted/no interference with sleep), 2 (moderate: patient aware of symptom but could conduct usual activities/ minimal interference with sleep), or 3 (severe: patient unable to conduct usual activities/symptom largely prevented sleep). Frequency was rated 0 never, 1 occasionally, 2 often, 3 very often.

At each visit the patients assessed their condition on two visual analogue scales, answering the questions: How was your heartburn last week? $(0=$ absent to $100=$ unbearable $)$ and How often did you have regurgitation last week? $(0=$ never to $100=$ almost continuously). A rating of excellent or good was assigned to the treatment if the main symptoms had disappeared or substantially improved, and moderate or poor if there had been little or no appreciable improvement. Any adverse experiences were noted.

\section{STATISTICS}

The cumulative proportion of patients in remission was estimated by means of the KaplanMeier product-limit method ${ }^{24}$ and the logrank test was used for the assessments of intergroup differences. Intragroup changes in symptom scores and visual analogue scale ratings were evaluated by means of the Wilcoxon signed rank test and intergroup differences by the MannWhitney $\mathrm{U}$ test.

The influence of several factors on time to healing and time to relapse of oesophagitis was assessed by means of multiple stepwise linear regression analysis. ${ }^{25}$ These factors were: sex, age, smoking, alcohol consumption, previous episode of oesophagitis, weight, initial severity of oesophagitis, total symptom score, and, in the maintenance trial, the maintenance treatment and the time to healing in the open cisapride treatment.

\section{Results}

HEALING PHASE

At the start of the study $62 \%$ of the patients had grade II to IV oesophagitis, the remainder having grade I (Table I). At the end of the healing phase, which was at week 8 in nearly half of the patients, week 12 in one third, and about week 16 in a fifth, 95 of the 138 patients $(69 \%)$ had grade 0,18 patients had grade $I, 14$ patients 


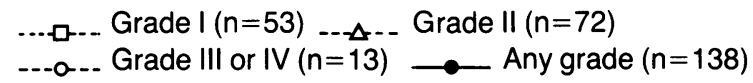

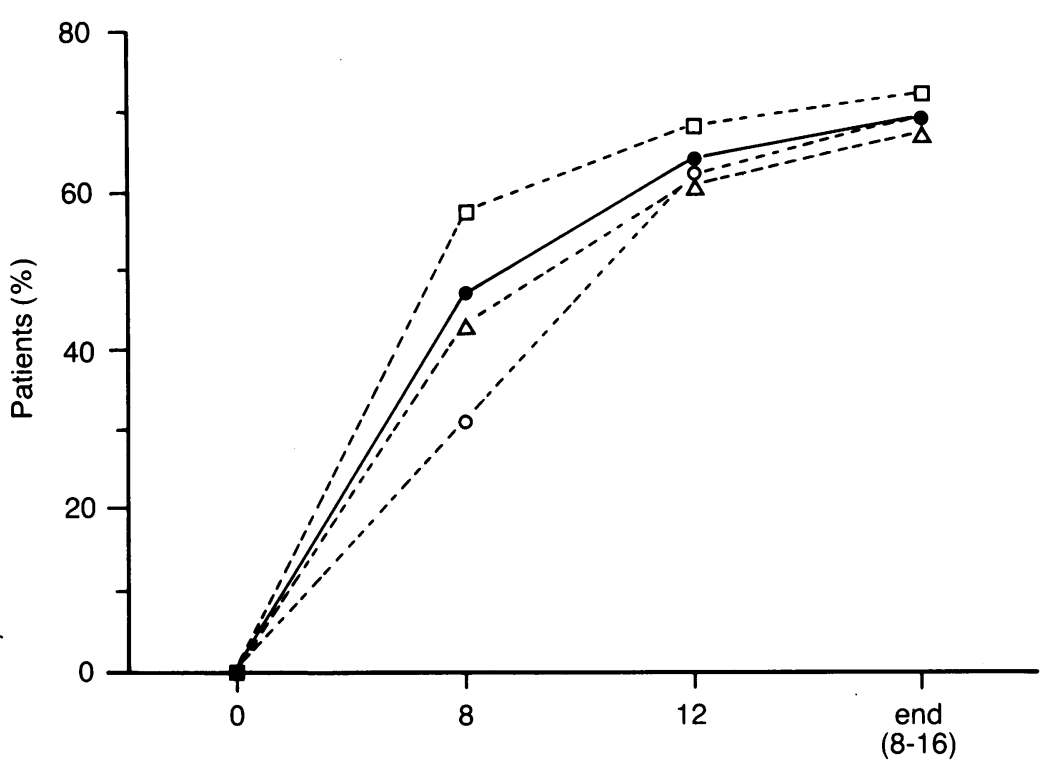

Time (weeks)

Figure 1: Open treatment phase: cumulative rates of endoscopic healing (grade 0) stratified according to the initial grade.

IV. Healing ccurred earlier in the patient
The visual analogue scale ratings given by the patients were in keeping with the investigator's symptom assessments: the mean scores for heartburn and regurgitation significantly $(\mathrm{p}<0.0001)$ decreased, from 65.6 at baseline to 26.7 at week 8 to $22 \cdot 8(-65 \%)$ at the end, and from 52.0 to $19 \cdot 6$ to $17 \cdot 8(-66 \%)$, respectively. At the end of the healing phase a global rating of excellent or good was given for $75 \%$ of the patients. Both in this phase and in the subsequent maintenance phase the use of antacids was limited.

\section{MAINTENANCE PHASE}

Of the 95 patients who were healed at the end of the first study phase, 14 were lost to follow up and 81 entered the maintenance phase. One of these was excluded from the efficacy analysis because of non-compliance with the study medication regimen. The data for the remaining 80 patients, 37 in the cisapride group and 43 in the placebo group, are given in Table I. Four patients withdrew without having a control endoscopy, two in the cisapride group (one who felt perfectly well at the end of the study refused endoscopy, and one who was also symptom free stopped treatment after eight weeks due to pregnancy), and two in the placebo group (withdrawal at 15 to 18 weeks).

By the end of the observation period oesophagitis had recurred in seven of the 35 cisapride patients $(20 \%)$ and in 16 of the 41 placebo patients (39\%) who had had a control endoscopy (Table III). The cumulative proportion of initially had grade I than in those who had grades II to IV, but at week 12 the healing rate was similar for grades I (72\%), II (67\%), and III/IV (69\%) (Fig 1).

Each of the four reflux symptoms assessed by the investigator improved significantly (Table II). The main symptom, daytime heartburn, occurred in $92 \%$ (moderate or severe in $76 \%$ ) of the patients at the start and in $57 \%(23 \%)$ at the end. Compared with the baseline the mean total severity score for the four reflux symptoms was decreased by $60 \%$ at week 8 and by $75 \%$ at week $12(67 \%$ at end $)$ of the healing phase. The improvement in postprandial epigastric discomfort paralleled the relief of reflux symptoms: the mean total severity score for the eight symptoms was 5.67 at the start and $2.09(-63 \%)$ at the end; each symptom was significantly improved $(p<0.0001$ except $p<0.001$ for early satiety and vomiting and $p=0.02$ for anorexia which were present in few patients). Changes in the frequency of symptoms were virtually identical to changes in severity.

TABLE II Changes from baseline in intensity of symptoms in the healing phase

\begin{tabular}{|c|c|c|c|c|}
\hline & \multirow{2}{*}{$\begin{array}{l}\text { Mean }(S E M) \\
\text { score at } \\
\text { baseline } \\
(n=138)\end{array}$} & \multicolumn{3}{|c|}{ Mean $\%$ change in score ${ }^{\star}$} \\
\hline & & $\begin{array}{l}\text { Week 8 } \\
(n=125)\end{array}$ & $\begin{array}{l}\text { Week } 12 \\
(n=51)\end{array}$ & $\begin{array}{l}E n d+ \\
(n=138)\end{array}$ \\
\hline \multicolumn{5}{|l|}{ Heartburn: } \\
\hline Day & $2.07(0.08)$ & -52 & -67 & -60 \\
\hline Night & $1.53(0.11)$ & -63 & -81 & -71 \\
\hline \multicolumn{5}{|l|}{ Regurgitation: } \\
\hline & $1 \cdot 34(0 \cdot 10)$ & -60 & -70 & -67 \\
\hline Night & $0.75(0 \cdot 10)$ & -75 & -91 & -80 \\
\hline
\end{tabular}

*Changes in scores were significant $(\mathrm{p}<0.0001$, Wilcoxon signed rank test) for all symptoms at all assessments.

+Week 8, 12, or 16 .
TABLE III Endoscopic relapse rates after six month maintenance treatment with cisapride or placebo according to the initial grade of oesophagitis

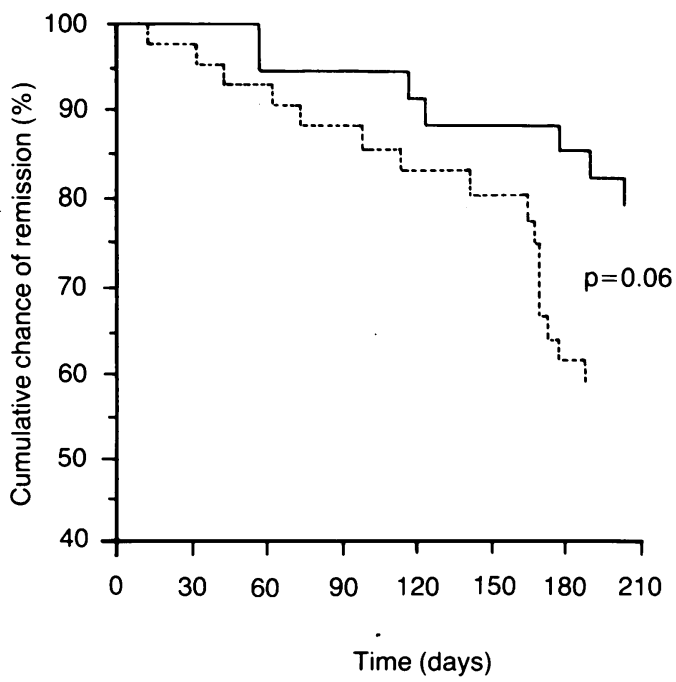

Figure 2: Double blind maintenance phase: relapse distribution curves.

\begin{tabular}{llll}
\hline & \multicolumn{4}{l}{ No(\%) of patients relapsed } \\
\cline { 2 - 4 } & Grade I & Grade II & Grade III or IV \\
\hline Cisapride & $2 / 17(12)$ & $3 / 16(19)$ & $2 / 4(50)$ \\
Placebo & $4 / 14(31)$ & $9 / 25(36)$ & $3 / 5(60)$ \\
\hline
\end{tabular}



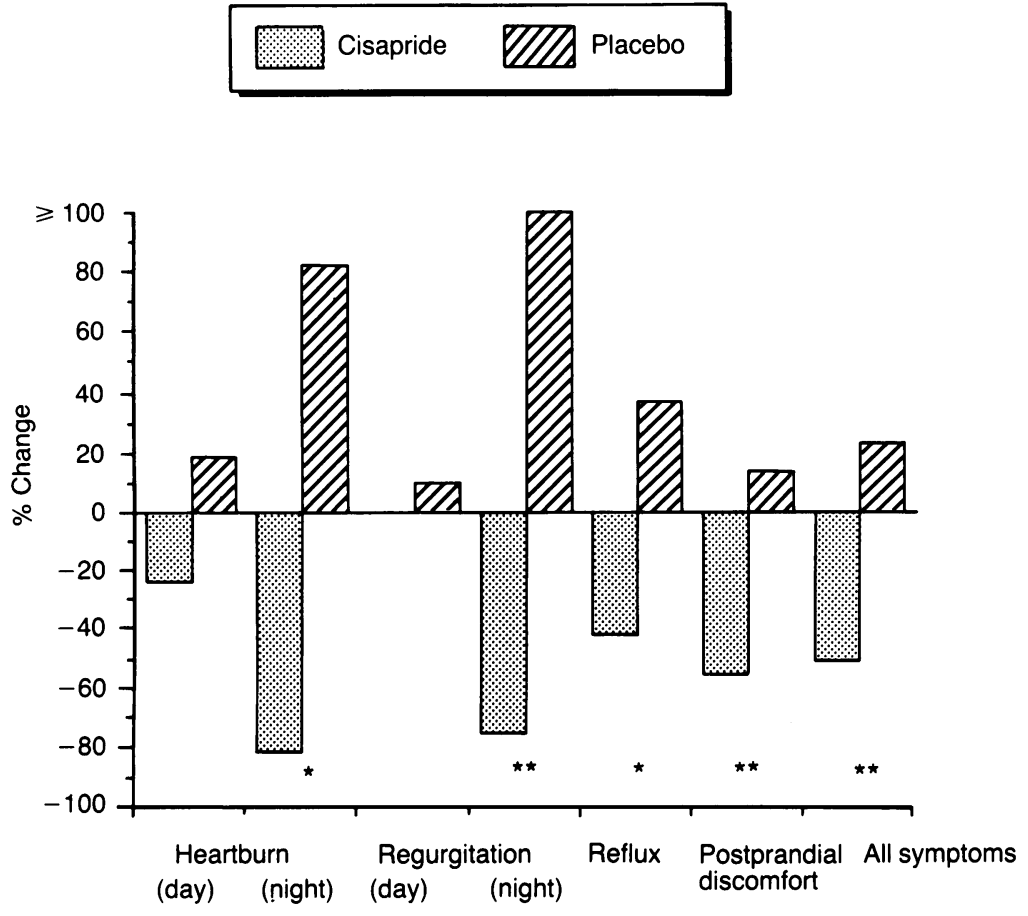

Figure 3: Per cent changes from baseline to end in severity scores for heartburn and regurgitation, day and night, the sum of these four symptoms (reflux), the symptoms of postprandial discomfort, and the cluster of all symptoms during the double blind maintenance phase. ${ }^{\star} p=0.02$ $\star \star p<0 \cdot 01$, cisapride $\mathrm{v}$ placebo.

\section{Symptoms}

patients in remission was higher $(\mathrm{p}=0.06)$ with cisapride than with placebo (Fig 2). In the cisapride group recurrence of heartburn or epigastric pain had caused five patients to report early (between weeks 8 and 17) for control endoscopy; the other two relapsed patients had no symptoms at the scheduled six month endoscopy (actually performed at weeks 27 and 29). In the placebo group nine patients returned for control endoscopy between two and 20 weeks because of recurrence of symptoms; in the remaining seven who relapsed, all of whom had symptoms (moderate or severe in five), symptoms requiring endoscopy occurred at the end of the trial, between weeks 23 and 27 .

The reduction in the severity of symptoms by the end is shown in Figure 3. At the beginning of the maintenance phase few patients had nighttime reflux: heartburn was absent in about $80 \%$ of patients in each group and regurgitation in about $90 \%$. In the cisapride group the remaining night-time symptoms almost completely disappeared, whereas in the placebo group they deteriorated. Daytime symptoms in patients entering the maintenance phase were virtually always mild, but they were slightly more frequent $(p \geq 0.09)$ in the placebo group: daytime heartburn was reported by $42 \%$ of the cisapride patients and $60 \%$ of the placebo patients, and regurgitation by $17 \%$ and $32 \%$. These symptoms tended to deteriorate in placebo patients and not in cisapride patients. Changes in total scores for the four reflux symptoms, the eight symptoms of postprandial epigastric discomfort, and all symptoms were significantly in favour of cisapride. As in the healing phase, frequency scores were similar to severity scores.

The mean visual analogue scale scores assigned by the patients for heartburn and regurgitation were initially lower than 20 in both groups; they further decreased in the cisapride patients (by $20 \%$ and $23 \%$ ) and increased in the placebo patients (by $29 \%$ and $10 \%$ ), but these changes were not significant. Overall, the end result was rated excellent and good, respectively, in $64 \%$ and $30 \%$ of the cisapride patients and in $38 \%$ and $32 \%$ of the placebo patients, and moderate or poor in $6 \%$ and $30 \%(p=0 \cdot 009)$.

DETERMINANTS OF HEALING AND RELAPSE

Multiple stepwise regression analysis suggested that endoscopic healing was related $(p=0.06)$ to the initial degree of oesophagitis (healing occurred later in patients with higher grades) but not to the total symptom score. On the other hand, this analysis showed that leaving aside the effect of treatment on relapse, the duration of remission tended to be longer for (a) a lower initial grade of oesophagitis $(p=0.08),(b)$ in agreement with the finding in the healing phase, a shorter time of healing $(p=0 \cdot 10)$, and (c) a lower total symptom score at the end of the healing phase $(p=0 \cdot 13)$ : patients, who despite endoscopic cure, still had symptoms at the end of the healing phase tended to relapse earlier than patients who were symptom free at that time. These correlations were based on the two groups combined. Calculations for the two groups separately showed that the contribution of the placebo group was significant $(\mathrm{p} \leq 0.02)$ for correlations (b) and (c) and that of the cisapride group $(p=0.02)$ for (a). Neither healing nor relapse correlated significantly with sex, age, weight, smoking, alcohol consumption, or previous oesophagitis.

Although no strict correlation between symptom severity and oesophageal lesions was found at the end assessment in the healing or maintenance phase, respectively, $85 \%$ and $89 \%$ of the patients with no symptom of reflux had endoscopic grade 0 , whereas $83 \%$ and $80 \%$ of the patients with grade I or higher had symptoms. Conversely, the presence of symptoms did not necessarily reflect mucosal damage and the absence of lesions did not guarantee the absence of symptoms (Table IV).

\section{ADVERSE EFFECTS}

In the healing phase nine patients had adverse experiences (five diarrhoea; one vomiting; one painful genitals and increased sweating; one increased reflux symptoms; one mild nausea and dizziness - this patient dropped out). In the maintenance phase adverse effects were reported by five patients in the cisapride arm (two constipa-

TABLE IV Presence of specific reflux symptoms $\mathrm{v}$ presence of oesophageal lesions at the end of each study phase (only patients in whom both heartburn and regurgitation, day and night, were assessed at the end control endoscopy are included)

\begin{tabular}{lcc}
\hline & \multicolumn{2}{c}{ Any lesions present } \\
\cline { 2 - 3 } Any reflux symptom present & Yes & No \\
\hline Healing phase & 34 & 52 \\
Yes & 7 & 41 \\
No & 16 & 22 \\
Maintenance phase & 4 & 31 \\
Yes & & \\
No & &
\end{tabular}

${ }^{\star}$ Cisapride plus placebo patients. 
tion; one dizziness; one increased bowel movements and loose stools; one generalised pruritus) and seven patients in the placebo arm (constipation, diarrhoea or abdominal pain in six, one each also having polyphagia and asthenia; extrasystoles at night in one). During neither of the two study phases did the treatment cause a clinically or statistically significant change in diastolic or systolic blood pressure or in weight.

\section{Discussion}

The findings confirm previous studies ${ }^{6-9}$ showing that cisapride is efficacious in healing oesophagitis. Endoscopic grade 0 was obtained in $69 \%$ of the patients. Although the response was slower in patients with a more severe condition, the end result in grade II (67\%) and grades III-IV $(69 \%)$ - the latter figure should be interpreted with caution since only 13 patients had this grade - was close to that in grade I $(72 \%)$. This is in keeping with the results of Lepoutre $e t$ al, who reported a $73 \%$ healing rate in grades II and III after eight to 16 weeks of treatment, ${ }^{6}$ and contrasts with findings for ranitidine, for which the healing rate had been reported to be lower for a higher initial severity. ${ }^{12} 2627$ There was no strict correlation between changes in symptoms and healing of lesions, but a 'one way' relation was found in that patients who were symptom free after treatment were unlikely to have mucosal damage. Smoking did not adversely affect healing in our study.

Unlike acute curative treatment, longterm treatment of esophagitis still poses problems. Maintenance with $\mathrm{H}_{2}$ receptor antagonists, at doses lower than those given for acute curative treatment (ranitidine $150 \mathrm{mg}$ once a day, famotidine $20-40 \mathrm{mg}$ once a day, cimetidine 400-800 mg twice a day), has not been shown to be efficacious in preventing symptom or endoscopic relapse compared with placebo. ${ }^{12-21}$ Similarly, one study with omeprazole showed that for patients to remain in remission a dose of $40 \mathrm{mg}$ once a day had to be given - that is, the dose given in the acute healing phase. ${ }^{22}$ However, prolonged treatment with omeprazole has not been adequately assessed either for efficacy or for safety. ${ }^{323}$ To date, one paper has suggested that prophylaxis of relapse may be achieved with the full therapeutic dose of ranitidine. ${ }^{28}$

Our study provides the first evidence for the efficacy of a prokinetic drug to maintain remission in patients with oesophagitis. The divergence of the relapse curves in the cisapride and the placebo groups was significant at the 0.06 level. Two factors were found to be of possible prognostic value. Firstly, the initial degree of oesophagitis and, related to this, the duration of the curative treatment (weakly) correlated with relapse. Secondly, in the total patient sample less severe symptoms of reflux at the start of the maintenance phase tended to be associated with longer remission. This is in keeping with the observations of Koelz et al during ranitidine treatment. ${ }^{12}$ As they suggested, symptoms that persist despite mucosal healing may indicate substantial gastro-oesophageal reflux, which is not suppressed with $\mathrm{H}_{2}$ blockers, and which, in turn, is more likely to result in the recurrence of oesophagitis after acid suppression is discontinued. The finding in our study that there was no significant correlation between symptoms and duration of remission in the cisapride group alone, suggests that this phenomenon does not apply to cisapride, which, in fact, prevents reflux itself.

It should be noted that prevention of relapse was achieved after healing with the same drug. Therefore, our study does not give any information about the prophylactic effect of cisapride in patients healed with acid suppressing drugs. Failure to limit acid reflux to a physiological level is likely to be the bottom line in the pathogenesis of reflux disease. There is good evidence that, rather than increased gastric secretion, disturbed motility - that is, a transient or basal decrease in lower oesophageal sphincter pressure - delayed gastric emptying and abnormal oesophageal clearing have a primary causal role in reflux disease. ${ }^{29}{ }^{30}$ In fact, gastric secretion, both basal acid output and fluid output, is normal in most oesophagitis patients. ${ }^{23}{ }^{31}$ Also, it has been suggested that relapse of oesophagitis is related to impaired motility: in patients healed after intensive short term treatment with cimetidine and metoclopramide, a lower oesophageal sphincter pressure of $\leq 10 \mathrm{~mm} \mathrm{Hg}$ was noted in all who relapsed early, but in only $40 \%$ of those who relapsed late. ${ }^{18}$

The efficacy of $\mathrm{H}_{2}$ blockers in healing oesophagitis most likely results from inhibition of gastric acid secretion, thus rendering the refluxate less acidic. Neither cimetidine nor ranitidine increases lower oesophageal pressure or oesophageal motility, decreases reflux, or accelerates gastric emptying. ${ }^{32-34}$ In oesophagitis patients who were healed with ranitidine $300 \mathrm{mg}$ twice a day, healing was not associated with any improvement of oesophageal peristaltic activity, which was disturbed in more than $90 \%$ of patients. ${ }^{35}$ The same phenomenon was observed with omeprazole. ${ }^{36-38}$

In the management of oesophagitis acid suppression is an efficient substitute for motility correction, but the feasibility of prolonged strong acid suppression is still controversial in view of the associated hypergastrinaemia. ${ }^{23}$ The pharmacological profile of cisapride is opposite to that of acid suppressing drugs. Cisapride does not alter gastric secretion ${ }^{39}$ or gastrin concentrations, ${ }^{40}$ but corrects deficiencies in lower oesophageal sphincter activity, oesophageal contractility, and gastric emptying, ${ }^{5}$ which are critical to the development of reflux disease.

Cisapride has been shown to be well tolerated, and, unlike other prokinetic drugs, has no extrapyramidal side effects and does not affect plasma prolactin concentrations. Longterm treatment ( $\geq$ one year), in diabetic gastroparesis for example, was not associated with abnormalities in haematology, biochemistry, or vital signs. $^{441}$ Therefore, cisapride has a good chance of being useful in preventing relapse of oesophagitis.

We thank Drs I Teichmann, L Lepoutre, C de Galocsy, J M Sente, A Vandermeeren, I L Coenegrachts, and E Mohr for their contribution to the trial. 
1 Castell DO. Future medical therapy of reflux esophagitis. 7 Clin Gastroenterol 1986; 8 (suppl 1): 81-5.

2 Scarpignato C. Pharmacological bases of the medical treatment of gastroesophageal reflux disease. Dig Dis 1988; 6: 117-48.

3 Tytgat GNJ, Nio CY. The medical therapy of reflux oesophagitis. Baillière's Clin Gastroenterol 1987; 1: 791-807.

4 McCallum RW, Prakash C, Campoli-Richards DM, Goa KL. Cisapride. A preliminary review of its pharmacodynamic and pharmacokinetic properties, and therapeutic use as a prokinetic agent in gastrointestinal motility disorders. Drugs 1988; 36: 652-81.

5 Verlinden $M$. Review article: role for gastrointestinal prokinetic agents in the treatment of reflux oesophagitis? Aliment Pharmacol Therap 1989; 3: 113-31.

6 Lepoutre L, Bollen J, Vandewalle N, et al. Therapeutic effects of cisapride in reflux oesophagitis: a double-blind placeboof cisapride in reflux oesophagitis: a double-blind placebo-
controlled study. In: Johnson AG, Lux G, eds. Progress in the controlled study. In: Johnson AG, Lux G, eds. Progress in the treatment of gastrointestinal motility disorders: the
cisapride. Amsterdam: Excerpta Medica, 1988: 63-5.

7 Baldi F, Bianchi Porro G, Dobrilla G, et al. Cisapride versus placebo in reflux oesophagitis. A multicenter double-blind trial. F Clin Gastroenterol 1988; 10: 614-8.

8 Evreux M, Fournet J, Galmiche JP, Soulé J, Vitaux P. Endoscopic and clinical evaluation of cisapride and cimetidine in reflux oesophagitis. Gastroenterology 1988; 94: A120.

9 Janisch HD, Hüttemann W, Bouzo MH. Cisapride versus ranitidine in the treatment of reflux esophagitis. Hepatoranitidine in the treatment of
gastroenterology 1988; 35: 125-7.

10 Sandmark S, Carlsson R, Fausa O, Lundell L. Omeprazole or ranitidine in the treatment of reflux esophagitis. Results of a ranitidine in the treatment of reflux esophagitis. Results of a
double-blind, randomized, scandinavian multicenter study double-blind, randomized, scandinavia

11 Hetzel DJ, Dent J, Reed WD, et al. Healing and relapse of severe peptic esophagitis after treatment with omeprazole. Gastroenterology 1988; 95: 903-12.

12 Koelz HR, Birchler R, Bretholz A, et al. Healing and relapse of reflux esophagitis during treatment with ranitidine. Gastroenterology 1986; 91: 1198-205.

13 Bright-Asare P, Behar J, Brand DL, et al. Effects of long-term maintenance cimetidine on gastroesophageal reflux disease. Gastroenterology 1982; 82: 1025.

14 Ottenjann R, Siewert JR, Heilman K, Neiss A, Döpper H. Treatment of reflux - oesophagitis. Results of a multicenter trial with cimetidine. In: Siewert JR, Hölscher AH, eds Proceedings of the international esophageal week. Gräfelfing Demeter Verlag, 1986: 190

15 Berlin R, Ebel D, Cook T. Famotidine (F) 20 HS \& 40 HS vs placebo $(P)$, in the maintenance therapy $(M T)$ of reflux esophagitis (RE). Results of a double-blind, multicenter trial. Gastroenterology 1989; 96: A39.

16 Glise $\mathrm{H}$. Healing, relapse rates and prophylaxis of reflux esophagitis. Scand 7 Gastroenterol 1989; 24 (suppl 156): 5764.

17 Sontag S, Vlahcevic ZR, Orr W, et al. Ranitidine vs placebo in long-term treatment of gastroesophageal reflux (GERD). long-term treatment of gastroesop

18 Lieberman DA. Medical therapy for chronic reflux esophagitis. Long-term follow-up. Arch Intern Med 1987; 147 1717-20.

19 Wesdorp ICE. Oesophagitis and its complications - medical treatment. Scand f Gastroenterol 1984; 19 (suppl 106): 8797.

20 Kaul B, Petersen H, Erichsen H, et al. Gastroesophageal reflux disease: acute and maintenance treatments with cimetidine. Scand F Gastroenterol 1986; 21: 139-45.

21 Festen HPM, Driessen WMM, Lamers CBH, van Tongeren $\mathrm{JHM}$. Cimetidine in the treatment of severe ulcerative reflux oesophagitis: results of an 8-week double-blind study and of subsequent long-term maintenance treatment. Neth 7 Med 1980; 23: 237-40.

22 Dent J, Klinkenberg-Knol E, Elm G, Eriksson K, Rikner L, Sölvell $\mathrm{L}$. Omeprazole in the long term management of patients with reflux esophagitis refractory to histamine $\mathrm{H}_{2}$-receptor antagonists. Gastroenterol Int 1988; 1 (suppl 1): 847.

23 Meuwissen SGM, Klinkenberg-Knol EC. Treatment of reflux oesophagitis with $\mathrm{H}_{2}$-receptor antagonists. Scand $\mathrm{f}$ Gastroenterol 1988; 23 (suppl 146): 201-13.

24 Lee ET. Statistical methods for survival data analysis. Belmont, California: Lifetime Learning Publications, 1981.

25 SAS Institute. SAS user's guide: statistics. Version 5 edition. Cary, NC: SAS Institute, 1985: 763-74.

26 Sandmark S, Carlsson R, Fausa O, Lundell L. Omeprazole or ranitidine in treatment of reflux esophagitis: double-blind comparative trial. Scand F Gastroenterol 1988; 23: 625-32.

27 Havelund T, Laursen LS, Skoubo-Kristensen E, et al. Omeprazole and ranitidine in the treatment of reflux oesophagitis. $B M F$ 1988; 296: 89-92.

28 Sherbaniuk R, Wensel R, Bailey R, et al. Ranitidine in the treatment of symptomatic gastroesophageal reflux disease. $\mathcal{F}$ Clin Gastroenterol 1984; 6: 9-15.

29 Richter JE. A critical review of current medical therapy for gastroesophageal reflux disease. $\mathcal{F}$ Clin Gastroenterol 1986; 8 (suppl 1): 72-80

30 Dent J, Holloway RH, Toouli J, Dodds WJ. Mechanisms of lower oesophageal sphincter incompetence in patients with lower oesophageal sphincter incompetence in patients with symptom 1020 .

31 Dubois A. Clinical relevance of gastroduodenal dysfunction in reflux esophagitis. $\mathcal{F}$ Clin Gastroenterol 1986; 8 (suppl 1): 1725.

32 Finkelstein W, Isselbacker KJ. Cimetidine. $N$ Engl f Med 1978; 299: 992-6.

33 Wallin L, Madsen T, Boesby S. Gastroesophageal function in normal subjects after oral administration of cisapride. Gut 1983; 24: 154-7.

34 Behar J, Brand DL, Brown FC, et al. Cimetidine in the treatment of symptomatic gastroesophageal reflux. A double-blind controlled trial. Gastroenterology 1978; 74: 441-8.

35 Robertson DAF, Aldersley MA, Shepherd H, Lloyd RS, Smith CL. H2-antagonists in the treatment of reflux oesophagitis: can physiological studies predict the response? Gut 1987; 28: 946-9.

36 Downton J, Dent J, Heddle R, Toouli J, Buckle PJ, MacKinnon MA, Wyman BJ. Elevation of gastric pH heals peptic oesophagitis. Gastroenterol Hepatol 1987; 2: 317-24.

37 Pedersen SA, Kraglund K, Vinter-Jensen L. The effects of omeprazole on gastro-oesophageal sphincter pressure, intragastric $\mathrm{pH}$, and the migrating motor complex in fasting healthy subjects. Scand $\mathcal{f}$ Gastroenterol 1987; 22: 725-30.

38 Horowitz M, Hetzel D, Buckle PJ, Chatterton BE, Shearman DJC. The effect of omeprazole on gastric emptying in patients with duodenal ulcer disease. Br f Clin Pharmacol patients with duode

39 Reyntjens A, Verlinden M, De Coster R, et al. Clinical pharmacological evidence for cisapride's lack of antidopaminergic or direct cholinergic properties. Curr Ther Res 1984; 36: 1045-52.

40 Koop H, Mönnikes H, Koop I, et al. Effect of the prokinetic drug cisapride on gastrointestinal hormone release. Scand $\mathcal{F}$ Gastroenterol 1986; 21: 907-13.

41 Verlinden M, Reyntjens A, Schuermans V. Safety profile of cisapride. In: Johnson AG, Lux G, eds. Progress in the treatment of gastrointestinal motility disorders: the role of cisapride. Amsterdam: Excerpta Medica, 1988: 30-6. 